\title{
VIOLÊNCIA FINANCEIRA CONTRA IDOSOS NO ÂMBITO FAMILIAR: UMA REVISÃO INTEGRATIVA
}

\author{
FINANCIAL VIOLENCE AGAINST THE ELDERLY IN THE FAMILY: AN \\ INTEGRATIVE REVIEW
}

\author{
Ana Patricia do Egito Cavalcanti de Farias ${ }^{1}$ \\ Antônia Lêda Oliveira Silva ${ }^{2}$ \\ Priscilla Leite Costa Andrade ${ }^{3}$ \\ Robson Antão de Medeiros ${ }^{4}$ \\ Ronaldo Bezerra de Queiroz ${ }^{5}$ \\ Sabine Helena Dantas ${ }^{6}$
}

RESUMO: OBJETIVO: Analisar a produção científica da violência financeira sofrida pelos idosos de forma a identificar a prevalência e as principais causas. MÉTODO: Trata-se de uma revisão integrativa da literatura, cuja busca foi realizada nos indexadores LILACS, MEDLINE e Scopus. Foram analisados 8 artigos que demonstraram a ocorrência de violência financeira contra o idoso. RESULTADOS: O gênero da maioria das vítimas de violência familiar foi composta pelo sexo feminino. Evidenciaram que os problemas de âmbito social e econômico influenciam certamente a relação entre vítima e agressor. No entanto, os dados referentes à denúncia corroboram o fato de que o idoso não faz queixa do próprio cônjuge, filho ou neto, justificado pelo número bastante inferior de vítimas que realmente denuncia o ato. Verificou-se muitas vezes, sentimentos de inibição, vergonha, medo e subnotificação desses casos. Na maioria dos artigos, a violência financeira ocorre juntamente com outros tipos de violência, principalmente a psicológica. CONCLUSÃO: Faz-se necessário voltar à atenção para esta temática tão relevante

\footnotetext{
1 Enfermeira, Mestranda Programa de Mestrado Profissional em Gerontologia da Universidade Federal da Paraíba, João Pessoa, Paraíba, Brasil.

2 Enfermeira, Profa. Dra. coordenadora do curso de Pós-graduação do Mestrado Profissional em Gerontologia da Universidade Federal da Paraíba, João Pessoa, Paraíba, Brasil.

${ }^{3}$ Advogado, Doutor em Ciências da Saúde - UFRN. Professor dos Cursos de Pós-graduação do Mestrado Profissional em Gerontologia e de Direito da UFPB.

${ }^{4}$ Médica, Mestranda Programa de Mestrado Profissional em Gerontologia da Universidade Federal da Paraíba, João Pessoa, Paraíba, Brasil.

5 Médico, Prof. Dr. do curso de Pós-graduação do Mestrado Profissional em Gerontologia da Universidade Federal da Paraíba, João Pessoa, Paraíba, Brasil.

6 Farmacêutica, Mestranda Programa de Mestrado Profissional em Gerontologia da Universidade Federal da Paraíba, João Pessoa, Paraíba, Brasil.
} 
que acomete a população idosa. O estudo comprovou que trata-se de um problema que afeta o bem-estar físico, emocional, social e financeiro do idoso.

Palavras chave: Idoso; Família; Violência.

ABSTRACT: OBJECTIVE: To analyze the scientific production of financial violence suffered by the elderly in order to identify the prevalence and the main causes. METHOD: This is an integrative literature review, whose search was performed using the LILACS, MEDLINE and Scopus indexers. Eight articles were analyzed that demonstrated the occurrence of financial violence against the elderly. RESULTS: The gender of most victims of family violence was composed of women. They showed that social and economic problems certainly influence therelationship between victim and aggressor. However, the data referring to the complaint corroborate the fact that the elderly person does not complain about their spouse, child or grandchild, justified by the much lower number of victims who actually report the act. There were many times, feelings of inhibition, shame, fear and underreporting of these cases. In most articles, financial violence occurs together with other types of violence, especially psychological. CONCLUSION: It is necessary to return attention to this theme so relevant that it affects the elderly population. The study proved that it is a problem that affects the physical, emotional, social and financial well-being of the elderly.

Descriptors: Elderly; Family; Violence 


\section{INTRODUÇÃO}

O envelhecimento populacional é uma realidade mundial. É um processo natural e individual, compreende todos os processos de transformação do organismo abrangendo mudanças fisiológicas, metabólicas, anatômicas, psicológicas e sociais. Tal fenômeno caracteriza-se pelo crescimento expressivo do número de pessoas idosas, ou seja, com mais de 60 anos de idade, resultante do declínio da fecundidade, da queda nas taxas de mortalidade e do aumento da expectativa de vida associado também às transformações socioeconômicas que determinaram grandes inovações científico-tecnológicas melhorando as condições de vida. Porém essas conquistas geraram aspectos negativos, como aumento da violência e maustratos (SOUSA, 2010; SILVA, 2012).

A Organização Mundial da Saúde (OMS) utiliza a definição violência como sendo um ato único ou repetido, ou a falta de ação adequada, proposital ou impensado que ocorre em qualquer relacionamento em que existe uma expectativa de confiança e que cause danos ou sofrimento a uma pessoa idosa (OMS, 2014).

Como forma de padronizar a classificação e estudo da violência dessa população, o relatório final do Estudo sobre Incidência Nacional de Violência, do Centro Nacional de Abusos contra Idosos de Washington, sintetizou os termos mais utilizados agrupando em categorias: abuso físico como sendo o uso de força física que pode resultar completamente em dano, dor ou prejuízo físico; o abuso sexual é o contato sexual não-consensual de qualquer pessoa com um idoso; o abuso emocional ou psicológico como a potencialização de angústia ou dor emocional ao idoso. O abuso financeiro é o uso ilegal ou impróprio dos bens ativos de idosos; o abandono é a deserção do idoso por um indivíduo que teve responsabilidade física ou tinha assumido o encargo por prover o cuidado; enquanto a negligência como sendo a recusa ou fracasso em cumprir obrigações ou deveres para com um idoso; e a autonegligência é caracterizada como o comportamento de um idoso que 
ameace sua própria segurança ou saúde (CORREIA, 2012; CASTRO, 2018; SHIMBO, LABRONICI, MANTOVANI, 2011).

Dentre os vários tipos de violência praticada contra a pessoa idosa torna-se relevante enfatizar um tipo em específico, a violência financeira que constitui uma das modalidades que mais tem crescido em número de incidência, onde o Estatuto do Idoso, Lei $n^{\circ} 10.741$, publicado em $1^{\circ}$ de outubro de 2003, tipifica a partir de seu art. 102 as condutas que se enquadram ao conceito de violência patrimonial contra a pessoa idosa, como por exemplo a retenção do cartão de aposentadoria, bem como a apropriação ou desvio de bens e de quaisquer outros rendimentos (pensão, aposentadoria ou outros ganhos) do idoso, dando a estes aplicação diversa de sua finalidade, qual seja, o benefício da pessoa idosa titular dos referidos proventos. Aplica-se pena de reclusão de 1 (um) a 4 (quatro) anos e multa.

Geralmente a referida prática ilícita está associada a maus-tratos físicos e psicológicos, e quando se desenvolve no espaço intrafamiliar é bastante complexa e delicada, em virtude de acarretar problemas com consequências devastadoras para os idosos, muitas vezes praticada por filhos/as, cônjuges, netos/as, irmãos, ou parentes e vizinhos próximos conhecidos da vítima, acaba sendo subdiagnosticada e subnotificada pela sua invisibilidade e difícil diagnóstico, devido à ligação emocional com o agressor, ao sentimento de culpa e vergonha, ocasionando baixa qualidade de vida, estresse psicológico, falta de segurança, lesões e traumas, bem como o aumento da morbidade e mortalidade. (BRASIL, 2003; BRASIL, 2014).

Diante dessa perspectiva, considerando o novo perfil populacional, sua vulnerabilidade e o aumento do índice desse tipo de violência tanto no contexto mundial como no Brasil, esse estudo se propôs a analisar a produção científica da violência financeira sofrida pelos idosos de forma a identificar a prevalência e as principais causas, pois trata-se de um problema que pode afetar o bem-estar físico, emocional e social do idoso, como também econômico.

\section{MÉTODO}


Trata-se de uma revisão integrativa da literatura, considerada como um método de pesquisa que permite a busca, avaliação crítica e a síntese das evidências disponíveis do tema investigado. Inclui a análise de pesquisas relevantes no meio científico referente ao tema investigado, além de identificar lacunas do conhecimento que necessitam serem preenchidas por meio da realização de novas pesquisas (POLIT e BECK, 2011).

A construção da revisão integrativa teve como etapas: 1) formulação da questão norteadora; 2) busca em bases de dados primários; 3) seleção e categorização dos estudos; 4) avaliação dos estudos selecionados; 5) discussão e interpretação dos resultados; e 6) síntese do conhecimento com recomendação para a prática.

Para guiar o estudo formulou-se a seguinte questão norteadora: Quais as evidências científicas acerca da violência financeira vivenciada por idosos junto a familiares?

A busca dos artigos foi realizada no mês de janeiro de 2020, nas bases de dados da Literatura Latino- Americana e do Caribe em Ciência da Saúde (LILACS), Medical Literature Analysis and Retrieval System Online (MEDLINE) e Elsevier B. V. (Scopus). A delimitação temporal dos artigos selecionados nos periódicos considerou o período dos últimos 5 anos de publicação. O período definido deve-se ao fato de os estudos da área de saúde terem uma evolução constante, sendo primordial a sua atualização. Foram realizados cruzamentos com descritores indexados no MeSH Terms: (family AND elder abuse AND domestic violence). Esses descritores foram combinados com o operador booleano AND a fim de refinar os estudos, conforme FIGURA 01. 
FIGURA 01: Fluxograma das estratégias de busca e processo de avaliação e seleção dos estudos. João pessoa, PB, 2020, Brasil.

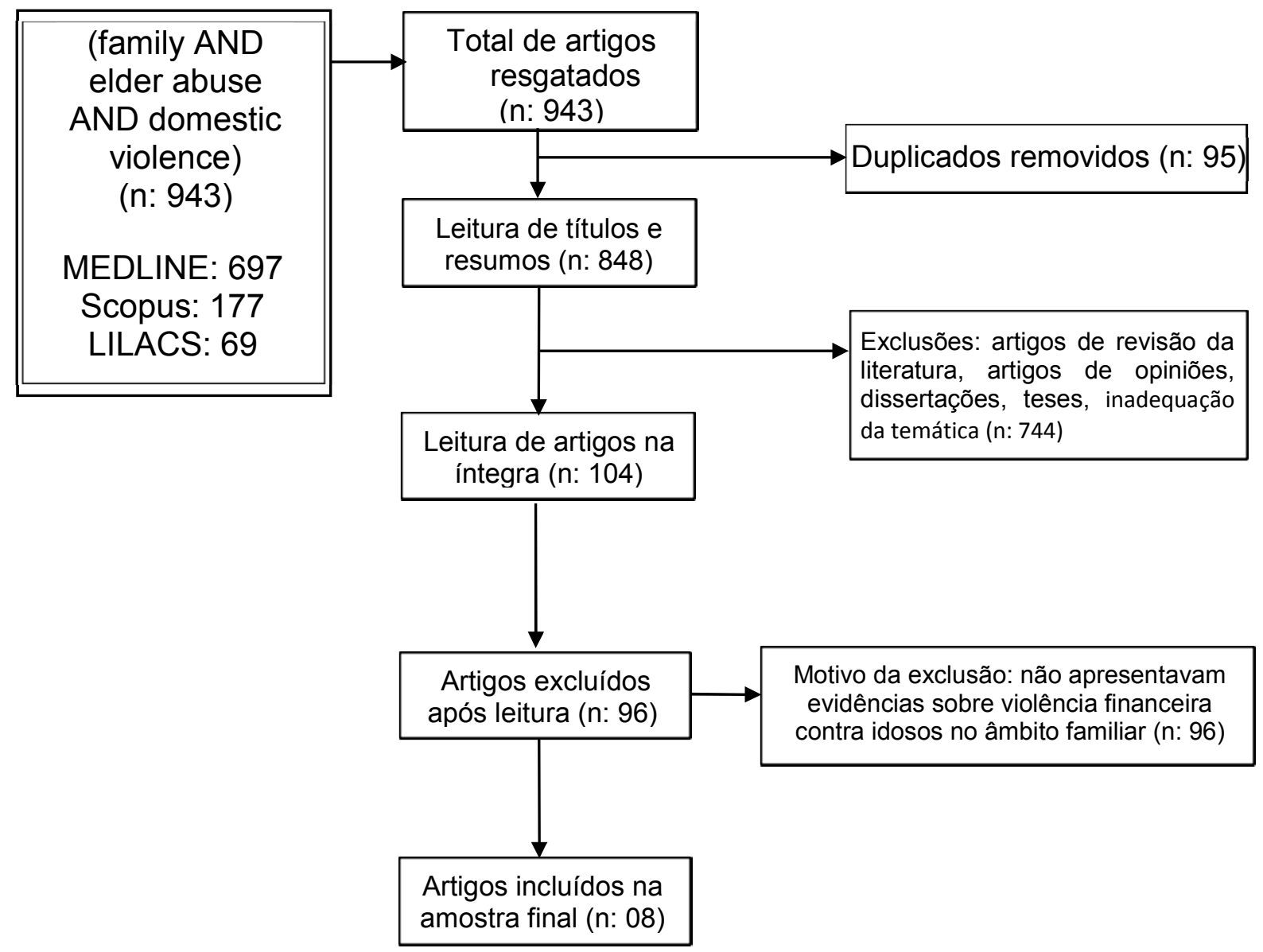

Fonte: dados da pesquisa.

Os critérios de inclusão definidos para a seleção dos artigos foram: artigos originais, pesquisas primárias desenvolvidas com seres humanos, artigos referentes a violência financeira contra idosos no âmbito familiar, mensurada por instrumentos validados em periódicos nacionais e internacionais, disponíveis nos idiomas inglês, espanhol e português na íntegra e indexadas nos referidos bancos de dados desenvolvidos no Brasil e no mundo.

Foram excluídos os artigos de revisão da literatura, artigos de opiniões, dissertações, teses, artigos que não respondiam à questão norteadora e os duplicados, ou seja, os artigos que apareceram em mais de uma base de dados que se contabilizaram uma única vez. Totalizaram-se 943 artigos científicos, e deste 
quantitativo, os artigos foram avaliados quanto a qualidade e adequação aos critérios de inclusão e exclusão entre as bases e após refinamento, a amostra final constituiu-se de 08 artigos.

Para a coleta dos dados, utilizou-se um instrumento composto de: base de dados, título, autores, ano de publicação, país, abordagem metodológica, amostra, periódico, objetivo e principais resultados.

No que se refere a seleção dos artigos, realizou-se a leitura criteriosa do título e resumo de cada publicação a fim de averiguar a consonância com a questão norteadora da investigação. Quando houve dúvida referente à inclusão ou exclusão do estudo, o mesmo foi lido na íntegra para reduzir o risco de perdas de publicações relevantes. Desse modo, aqueles que não abordaram a temática foram descartados na segunda análise. Respeitaram-se os aspectos éticos, referenciando-se os autores consultados para a concretização desta revisão.

\section{RESULTADO E DISCUSSÃO}

Na presente revisão integrativa, foram selecionados um total de 8 artigos que demonstraram a ocorrência de violência financeira contra o idoso. No estudo realizado por Gil e colaboradores (2015), em que apresenta dados sobre violência contra pessoas com 60 e mais anos residentes em Portugal, 47,5\% das vítimas relataram sofrer violência financeira. $O$ resultado dessa pesquisa foi semelhante ao encontrado no trabalho de Santos et al (2019), em que 58,9\% dos boletins de ocorrência numa Delegacia de Segurança e Proteção ao Idoso corresponderam à violência econômico-financeira. Numa pesquisa realizada por Silva-Fhon e colaboradores com idosos residentes do distrito de Breña, no Peru, a prevalência de violência financeira foi relatada em $53,1 \%$ deles. Nos Estados Unidos, de acordo com o estudo de Knight e equipe (2019), a porcentagem foi um pouco maior, onde $65,4 \%$ dos idosos do sul da Califórnia perceberam que estavam sofrendo abuso financeiro. 
Já na pesquisa realizada por Kołodziejczak e colaboradores, numa cidade da Polônia, a prevalência de violência financeira contra o idoso foi relatada em $8,8 \%$ dos casos. Resultado próximo foi observado num estudo promovido por CarmonaTorres, no ano de 2017, em que o abuso econômico foi registrado em 13,33\% dos participantes. No trabalho realizado por Diel e Barbiani (2018) no município de São Leopoldo, Rio Grande do Sul, a violência patrimonial foi responsável por $6 \%$ das denúncias. Dentre os artigos selecionados, o estudo feito por Claudia Curcio, na Colômbia, foi o que demonstrou menor ocorrência de violência econômica na população idosa $(1,3 \%)$.

Como é possível visualizar nos resultados da tabela 01 (Quadro de intervenção), o gênero da maioria das vítimas de violência familiar foi composta pelo sexo feminino. Com isso, pode-se dizer que o gênero influencia a probabilidade de uma pessoa idosa sofrer maus- tratos, como é o caso de uma investigação realizada nos Estados Unidos, que comparou casos de violência financeira e física e as dinâmicas judiciais envolvidas, constatando que as vítimas que sofreram violência financeira eram composta, em sua maioria, por mulheres $(67,7 \%)$. Os resultados também corroboraram o estudo realizado em Málaga, na Espanha, no qual, dos 259 casos de maus-tratos em idosos analisados, 77,6\% das vítimas eram mulheres (IBORRA, 2008; PAYNE, STRASSER, 2012; CASTILLA-MORA et al., 2014; CARMONA-TORRES, 2015). 
Quadro 01 - Caracterização dos estudos selecionados segundo identificação, objetivos, tipo de estudo, amostragem e principais resultados. João Pessoa, PB, Brasil, 2020.

\begin{tabular}{|c|c|c|c|c|}
\hline Periódico & $\begin{array}{c}\text { Autores, } \\
\text { Ano/País do } \\
\text { Estudo }\end{array}$ & Objetivo & Tipo de Estudo & $\begin{array}{l}\text { Amostra/Principais } \\
\text { Resultados }\end{array}$ \\
\hline $\begin{array}{l}\text { Colombia } \\
\text { Medica (Cali) }\end{array}$ & $\begin{array}{l}\text { CURCIO et a } \\
\text { (2019); Colômbia }\end{array}$ & 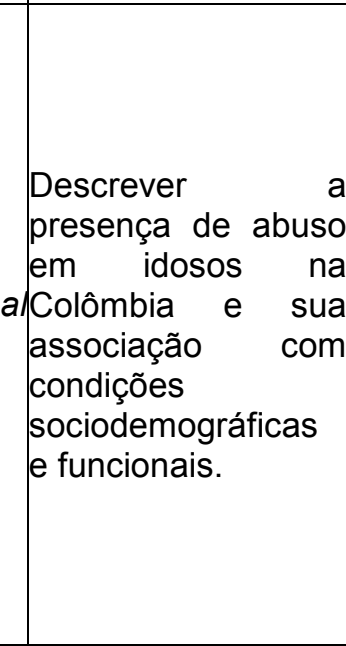 & $\begin{array}{l}\text { Estudo } \\
\text { observacional, } \\
\text { transversal } \\
\text { descritivo }\end{array}$ & $\begin{array}{l}15,1 \% \text { dos idosos na } \\
\text { Colômbia relataram algum } \\
\text { tipo de abuso e mais de } 50 \% \\
\text { relataram mais de uma forma } \\
\text { de abuso. Especificamente, } \\
\text { verificou-se que o abuso } \\
\text { econômico foi relatado em } \\
1,3 \% \text { da população idosa } \\
\text { elombiana. Esse tipo de } \\
\text { violência foi encontrado } \\
\text { predominantemente em } \\
\text { indivíduos do sexo masculino, } \\
\text { com nível de escolaridade } \\
\text { maior que } 5 \text { anos, em idosos } \\
\text { que moram sozinhos e na } \\
\text { zona rural. }\end{array}$ \\
\hline $\begin{array}{l}\text { Annals of } \\
\text { Agricultural } \\
\text { and } \\
\text { Environmenta } \\
\text { I Medicine }\end{array}$ & $\begin{array}{lr}\text { KOLODZIEJCZAK } \\
; & \text { TERELAK; } \\
\text { BULSA } & (2019) ; \\
\text { Polônia } & \end{array}$ & 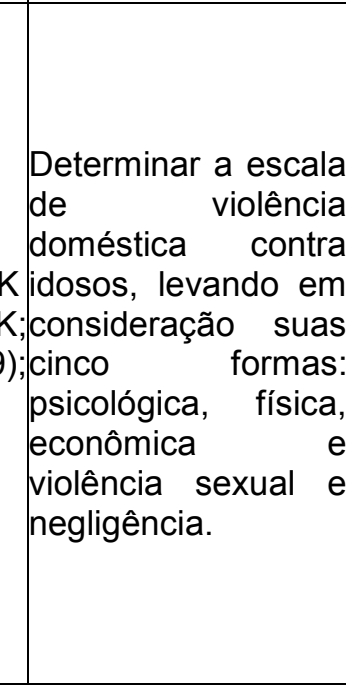 & $\begin{array}{l}\text { Método de } \\
\text { amostragem } \\
\text { representativo } \\
\text { por meio de } \\
\text { entrevista de } \\
\text { auditoria }\end{array}$ & $\begin{array}{l}\text { A amostra participante do } \\
\text { estudo foi constituída por } 137 \\
\text { idosos residentes da zona } \\
\text { rural da Polônia. Destes, } \\
8,8 \% \text { dos participantes da } \\
\text { pesquisa declararam que } \\
\text { sofriam vítimas de violência } \\
\text { econômica. Nos } 6 \text { meses } \\
\text { anteriores a pesquisa, } 3,65 \% \\
\text { dos idosos experimentaram } \\
\text { excessivo e persistente } \\
\text { controle sobre suas despesas } \\
\text { por outros membros da } \\
\text { família. } 2,92 \% \text { dos } \\
\text { entrevistados admitiram ter } \\
\text { sido forçado a entregar seu } \\
\text { dinheiro. }\end{array}$ \\
\hline
\end{tabular}




\begin{tabular}{|c|c|c|c|}
\hline $\begin{array}{l}\text { Revista da } \\
\text { Escola de } \\
\text { Enfermagem } \\
\text { da USP }\end{array}$ & $\begin{array}{l}\text { SANTOS et } \\
\text { (2019); Brasil }\end{array}$ & 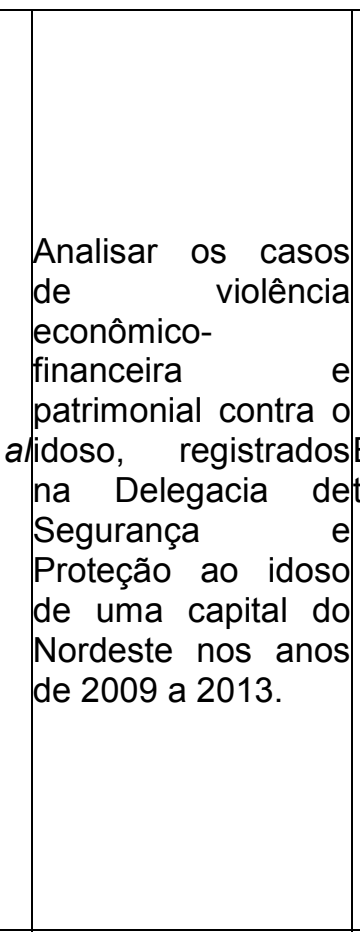 & 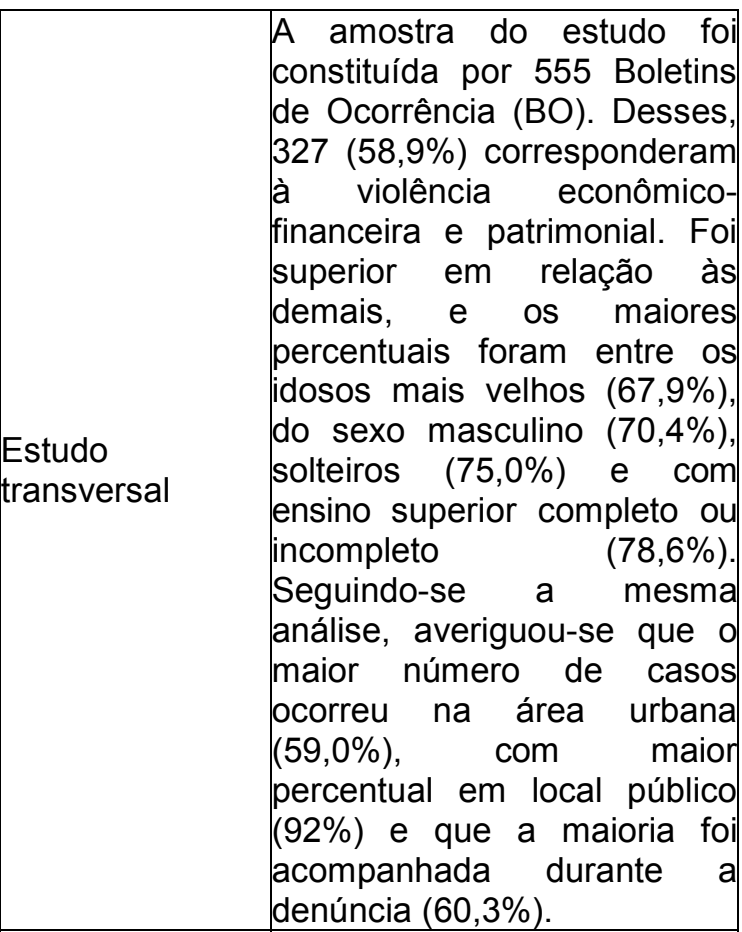 \\
\hline $\begin{array}{l}\text { Cadernos } \\
\text { Saúde } \\
\text { Pública }\end{array}$ & $\begin{array}{l}\text { e } \\
\text { GIL et al }(2 C \\
\text { Portugal }\end{array}$ & 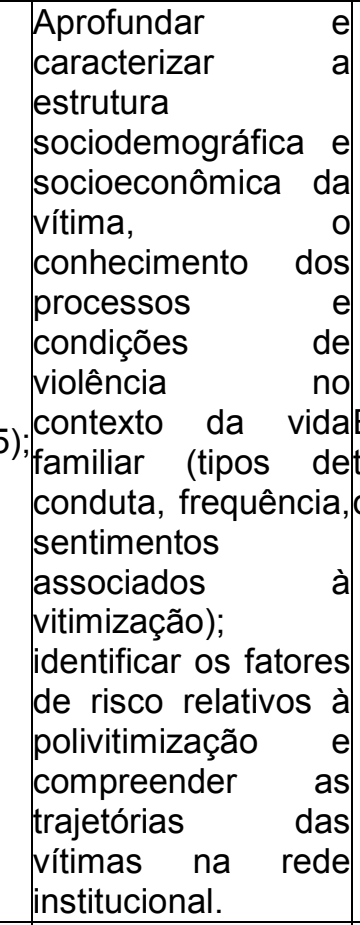 & $\begin{array}{l}\text { A amostra não probabilística } \\
\text { foi constituída por } 510 \text { vítimas } \\
\text { de violência em contexto } \\
\text { familiar. A violência financeira } \\
\text { foi reportada em } 47,5 \% \text { das } \\
\text { vítimas. Mais da metade das } \\
\text { vítimas era casada e } \\
\text { integrava um núcleo familiar } \\
\text { composto, sobretudo, por } \\
\text { duas pessoas. A maioria } \\
\text { efrequentou o ensino básico } \\
(65,7 \%) \text { ou não tinha } \\
\text { escolaridade (22,9\%). As } \\
\text { vítimas, na maioria mulheres, } \\
\text { tinham uma média de idade } \\
\text { de } 70,7 \text { anos. A maioria dos } \\
\text { agressores pertencia à família } \\
\text { nuclear, nomeadamente, } \\
\text { cônjuges ou companheiros, } \\
\text { filhos/enteados } \\
\text { filhas/enteadas. }\end{array}$ \\
\hline $\begin{array}{l}\text { International } \\
\text { Psychogeriatr } \\
\text { ics }\end{array}$ & $\mid \begin{array}{l}\text { KNIGHT et } \\
(2016) ; \text { California }\end{array}$ & $\begin{array}{l}\text { Explorar o efeito } \\
\text { dos fatores vítima e } \\
\text { percebedor ra na } \\
\text { alpercepção do abuso } \\
\text { financeiro de idosos } \\
\text { no contexto da } \\
\text { Teoria da Atividade } \\
\text { de Rotina (RAT). }\end{array}$ & 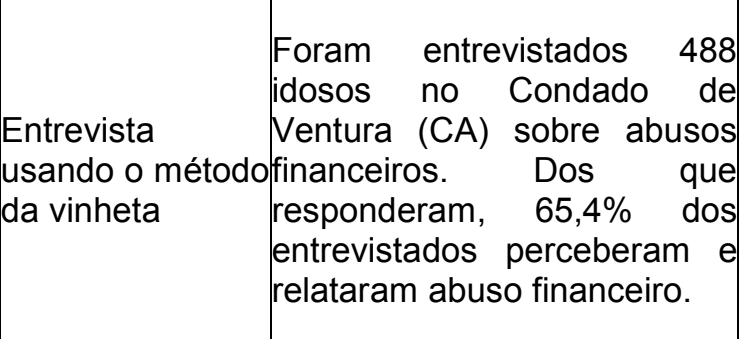 \\
\hline
\end{tabular}




\begin{tabular}{|c|c|c|c|}
\hline $\begin{array}{l}\text { Textos } \\
\text { Contextos }\end{array}$ & 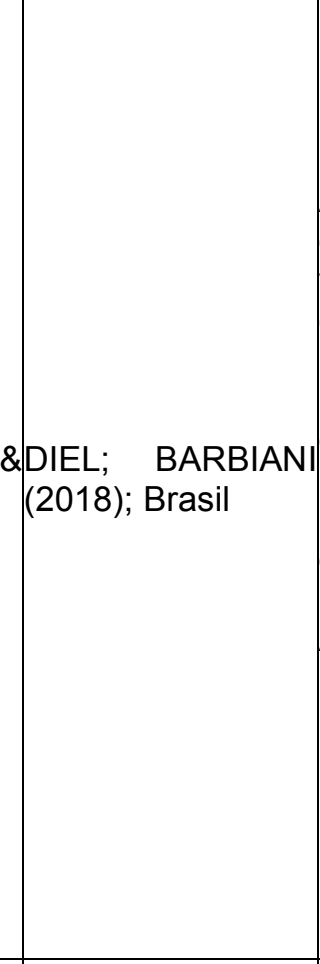 & 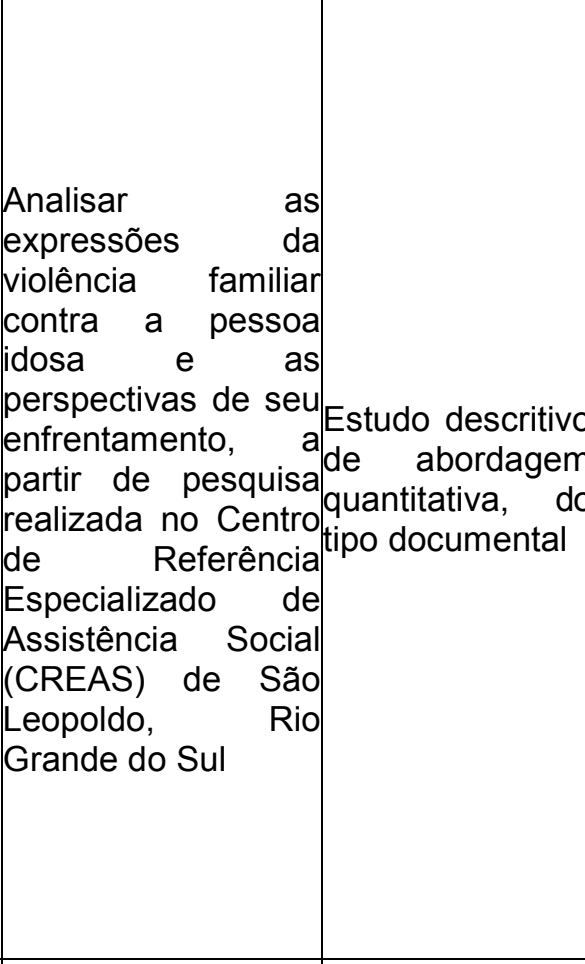 & $\begin{array}{l}\text { As violências patrimonial, } \\
\text { física e o abandono foram } \\
\text { responsáveis por } 6 \% \text { das } \\
\text { denúncias, respectivamente. } \\
\text { A concentração dos casos de } \\
\text { violência familiar ocorreu nas } \\
\text { seguintes faixas etárias: entre } \\
80 \text { e } 89 \text { anos (38\%), entre } 60 \\
\text { e } 69 \text { anos (28\%), seguido por } \\
70 \text { e } 79 \text { anos (23\%). Quanto } \\
\text { ao sexo, as mulheres foram } \\
\text { as maiores vítimas, atingindo } \\
\text { o percentual de } 78 \% \text {. Em se } \\
\text { tratando da situação civil das } \\
\text { pessoas idosas, } 43 \% \text { da } \\
\text { amostra era composta por } \\
\text { viúvos(as). } \\
\text { configuração Sobre } \\
\text { observou-se que a maioria } \\
\text { (64\%) residia com a família, } \\
\text { sendo } 28 \% \text { com filho(as) e } \\
34 \% \text { com família ampliada } \\
\text { (filho/as, genro/nora, netos e } \\
\text { bisnetos). }\end{array}$ \\
\hline $\begin{array}{l}\text { Revista } \\
\text { Latino- } \\
\text { Americana de } \\
\text { Enfermagem }\end{array}$ & $\begin{array}{l}\text { CARMONA- } \\
\text { TORRES et al } \\
\text { e(2017); llhas dos } \\
\text { Açores }\end{array}$ & \begin{tabular}{ll|l} 
Dimensionar & os \\
maus- tratos & contra \\
as pessoas & idosas \\
vulneráveis & no & \\
ambiente familiar e & Estudo \\
comunitário & nas & Observacional \\
llhas dos Açores, & descritivo do tipc \\
identificar fatores de & transversal \\
risco para maus- & \\
tratos e definir o \\
perfil do idoso \\
maltratado.
\end{tabular} & $\begin{array}{l}\text { No total, } 212 \text { idosc } \\
\text { participaram do estud } \\
13,33 \% \text { relataram sofr } \\
\text { abuso financeiro. } 72,2 \% \text { era } \\
\text { mulheres e } 27,8 \% \text { era } \\
\text { homens, com uma média } \\
\text { idade de } 74,91 . \text { A maioria e } \\
\text { casada }(44,2 \%) \text { e } 82,7 \\
\text { tinham filhos. O idos } \\
\text { identificou como agress } \\
\text { seus filhos }(43,45 \%)\end{array}$ \\
\hline $\begin{array}{l}\text { Revista de la } \\
\text { Facultad de } \\
\text { Medicina }\end{array}$ & $\begin{array}{l}\text { SILVA-FHON et } \\
(2015) ; \text { Peru }\end{array}$ & 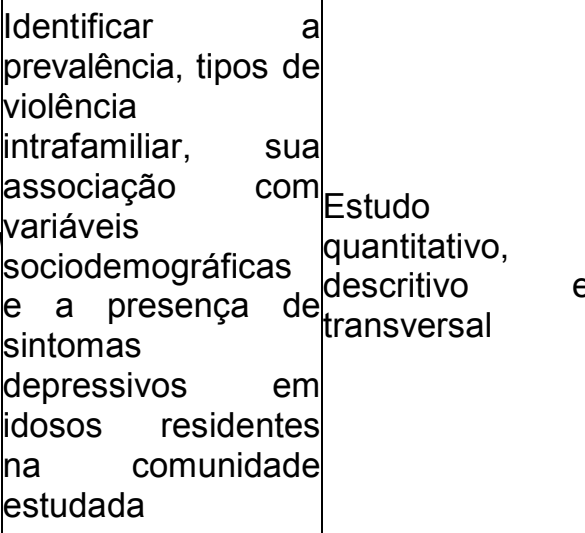 & $\begin{array}{l}\text { Dos } 369 \text { participantes } \\
\text { pesquisa, } 53,1 \% \text { relatara } \\
\text { sofrer abuso financeir } \\
\text { Observou-se prevalêno } \\
\text { feminina entre as vítim } \\
(55,8 \%), 23,6 \% \text { composta p } \\
\text { adultos acima de } 65 \text { anos } \\
69 \text { anos, } 44,7 \% \text { tinham a } \\
\text { seis anos de estudo e } 46,6 \\
\text { eram casados. }\end{array}$ \\
\hline
\end{tabular}

Os resultados do presente estudo evidenciaram que os problemas de âmbito social e econômico influenciam certamente a relação entre vítima e agressor. No entanto, os dados referentes à denúncia corroboram o fato de que o idoso não faz 
queixa do próprio cônjuge, filho ou neto, justificado pelo número bastante inferior de vítimas que realmente denuncia o ato. Evidenciando muitas vezes, sentimentos de inibição, vergonha, medo e subnotificação desses casos (OLIVEIRA et al., 2013; GIL et al., 2015).

Verificou-se também, que na maioria dos artigos, a violência financeira ocorre juntamente com outros tipos de violência, principalmente a psicológica. Esse fato é mais intenso e presente na sociedade do que imaginávamos, talvez por ser um fenômeno muitas vezes subdiagnosticado, principalmente porque os sentimentos de culpa e de vergonha por parte do idoso vítima da violência, se juntam ao medo de represália por parte dos agressores ou dos que os negligenciam (BRASIL, 2014).

\section{CONCLUSÃO}

Diante do exposto faz-se necessário voltar à atenção para esta temática tão relevante que acomete a população idosa. O estudo comprovou que trata-se de um problema que afeta o bem-estar físico, emocional, social e financeiro do idoso.

Para resolver referidas práticas ilícitas deve haver mais e uma ampliação das campanhas sobre a violência contra a pessoa idosa, sobretudo no tocante as questões de violência financeira no âmbito familiar, de acordo com os dados da pesquisa realizada, além de um estímulo a troca de conhecimentos e fortalecimento de vínculo transgeracional, no intuito de evitar que este grupo populacional seja visto de forma secundária pela sociedade vigente. 


\section{REFERÊNCIAS BIBLIOGRÁFICAS}

BRASIL. Estatuto do Idoso. Lei $\mathbf{n}^{\circ} \mathbf{1 0 . 7 4 1}$, de $1^{\circ}$ de outubro de 2003. Dispõe sobre o Estatuto do Idoso e dá outras providências. 2003. Disponível em: http://www.planalto.gov.br/ccivil_03/leis/2003//10.741.htm. Acesso em: 15 fev. 2020.

BRASIL. Presidência da República. Secretaria de Direitos Humanos. Manual de enfrentamento à violência contra a pessoa idosa. Brasília, 2014. Disponível em: http://www.sdh.gov.br/assuntos/pessoa-idosa/publicacoes/violencia-contra-a-pessoaidosa.

Acesso em: 23 jan. 2020.

CARMONA-TORRES, Juan Manuel et al. Elder abuse within the family environment in the Azores Islands / Maus-tratos no ambiente familiar contra idosos nas Ilhas dos Açores. Revista Latino-Americana de Enfermagem, [s.I.], v. 25, 21 set. 2017. Disponível em: http://www.revenf.bvs.br/scielo.php?script=sci_arttext\&pid=S0104-11692017000100372. Acesso em: 22 jan. 2020.

CASTILLA-MORA, Rosario; PALMA-GARCíA, Maria de Las Olas. El maltrato a personas mayores en el ámbito familiar. Aproximación a la situación en Málaga (España). Trabajo Social global-Global Social Work: Revista de investigaciones en intervención social, 2014. Disponível em: https://dialnet.unirioja.es/servlet/articulo?codigo=5304718. Acesso em: 28 jan. 2020.

CASTRO, Vivian Carla de; RISSARDO, Leidyani Karina; CARREIRA, Lígia. Violência contra osidosos brasileiros: uma análise das internações hospitalares. Revista Brasileira de Enfermagem, [s.I.], v. 71, n. 2, p.777-785, 2018. Fap UNIFESP (SciELO). http://dx.doi.org/10.1590/0034-7167-2017-0139. Disponível em: http://www.scielo.br/scielo.php?script=sci_arttext\&pid=S003471672018000800777\&lng=pt \&nrm=iso\&tlng=pt. Acesso em: 22 jan. 2020.

CORREIA, Thyago Moreira Paranhos et al. Perfil dos idosos em situação de violência atendidos em serviço de emergência em Recife-PE. Revista Brasileira de Geriatria e Gerontologia, Rio de Janeiro, v. 15, n. 3, p. 529-536, jul/set. 2012. http://dx.doi.org/10.1590/S180998232012000300013.

http://www.scielo.br/scielo.php?script=sci_arttext\&pid=S1809-

98232012000300013\&lng=en\&nrm=iso. Acesso em: 22 jan. 2020.

CURCIO, Carmen-Lucia; PAYÁN-VILLAMIZAR, Claudia; JIMÉNEZ, Abelardo; GÓMEZ, Fernando. Abuse in Colombian elderly and its association with socioeconomic conditions and functionality. Colombia Medica, [s.I.], p. 77-88, 30 jun. 2019. Disponível em: https://www.ncbi.nlm.nih.gov/pubmed/31607765>. Acesso em: 22 jan.2020.

DIEL, Marciane; BARBIANI, Rosângela. Violência familiar contra a pessoa idosa: expressões do fenômeno e perspectivas para o seu enfrentamento. Textos \& Contextos, Porto Alegre, v. 17, n. $2, \quad$ p. $\quad 379-392, \quad 2018.20$ Disponível em: http://revistaseletronicas.pucrs.br/ojs/index.php/fass/article/view/27484/17738. Acesso em: 23 jan. 2020

GIL, Ana Paula et al. Estudo sobre pessoas idosas vítimas de violência em Portugal: sociografia da ocorrência. Cadernos de Saúde Pública, [s.I.], v. 31, n. 6, p.1234-1246, jun. 2015. FapUNIFESP (SciELO). http://dx.doi.org/10.1590/0102-311x00084614. Disponível em: https://www.ncbi.nlm.nih.gov/pubmed/26200371. Acesso em: 23 jan 2020.

IBORRA, Isabel. Maltrato de personas mayores en la família en España [Elder abuse in the family in Spain]. Valencia: Fundación de la Comunitat Valenciana para el Estudio de la 
Violencia, 2008. Disponível em: https://dialnet.unirioja.es/servlet/libro?codigo=615979.

Acesso em: 28 jan. 2020.

KNIGHT, Bob G. et al. Influences on the perception of elder financial abuse among older adults in Southern California. International Psychogeriatrics, [s.I.], v. 28, n. 1, p. 163-169, 4 maio 2015. Cambridge University Press (CUP). http://dx.doi.org/10.1017/s1041610215000587. Disponível em: https://www.ncbi.nlm.nih.gov/pmc/articles/PMC6345643/. Acesso em: 23 jan. 2020.

KOłODZIEJCZAK, Sebastian; TERELAK, Albert; BULSA, Marek. Domestic violence against seniors in rural areas of West Pomerania, Poland. Annals Of Agricultural And Environmental Medicine, [s.l.], v. 26, n. 1, p. 92-96, 22 mar. 2019. Institute of Rural Health. http://dx.doi.org/10.26444/aaem/92208. Disponível

https://www.ncbi.nlm.nih.gov/pubmed/30922036. Acesso em: 23 jan. 2020.

OLIVEIRA, Annelissa Andrade Virgínio de et al. Maus-tratos a idosos: revisão integrativa da literatura. Revista Brasileira de Enfermagem, [s.I.], v. 66, n. 1, p. 128-133, fev. 2013. FapUNIFESP (SciELO). http://dx.doi.org/10.1590/s0034-71672013000100020. Disponível em: http://www.scielo.br/scielo.php?script=sci_arttext\&pid=S003471672013000100020\&lng=en \&nrm=iso. Acesso em: 20 jan. 2020.

Organização Mundial de Saúde (OMS). Global status report on violence prevention, 2014. World Health Organization. Disponivel em: https://apps.who.int/iris/handle/10665/145086.

Acesso em: 24 jan. 2020.

PAYNE, Brian K.; STRASSER, Sheryl M.. Financial exploitation of older persons in adult care settings: comparions to physical abuse and the justice systems's response. Journal of Elder Abuse \& Neglect, [s.I.], v. 24, n. 3, p. 231-250, jul. 2012. Informa UK Limited. http://dx.doi.org/10.1080/08946566.2011.653315

POLIT, Denise F.; BECK, Cheryl Tatano. Fundamentos de pesquisa em enfermagem: Avaliação de evidências para a prática de enfermagem, 7. ed. Porto Alegre: Artmed; 2011.

SANTOS, Ana Maria Ribeiro dos et al. Violência econômico-financeira e patrimonial contra o idoso: estudo documental. Revista da Escola de Enfermagem da USP, [s.I.], v. 53, 2019. FapUNIFESP (SciELO). http://dx.doi.org/10.1590/s1980-220x2017043803417. Disponível em: https://www.ncbi.nlm.nih.gov/pubmed/30673050. Acesso em: 23 jan. 2020.

SILVA-FHON, Jack Roberto et al. Domestic violence in older people living in the district of Breña, Peru. Revista de la Facultad de Medicina, [s.I.], v. 63, n. 3, p. 367-375, 25 ago. 2015. Universidad Nacional de Colombia. http://dx.doi.org/10.15446/revfacmed.v63n3.44743. Disponivel em: http://www.scielo.org.co/scielo.php?script=sci_arttext\&pid=S012000112015000300004. Acesso em: 23 jan. 2020.

SILVA, Marylane Viana; FIGUEIREDO, Maria do Livramento Fortes. Idosos institucionalizados: Uma reflexão para o cuidado de longo prazo. Enfermagem em Foco, [s.I.], v. 1, n. 3, p. 22-24, 2012. Disponível em: http://revista.cofen.gov.br/index.php/enfermagem/article/viewFile/215/136. Acesso em: 23 jan. 2020.

SHIMBO, Adriano Yoshio; LABRONICI, Maria Liliana; MANTOVANI, Maria de Fátima. Reconhecimento da violência intrafamiliar contra idosos pela equipe da estratégia saúde da família. Escola Anna Nery. Revista de Enfermagem, [s.I.], v. 15, n. 3, p.506-510, jul.-set. 2011. Disponivel em: http://revistaenfermagem.eean.edu.br/detalhe_artigo.asp?id=671.

Acesso em: 23 jan. 2020.

SOUSA, Danúbia Jussana de et al. Maus-tratos contra idosos: atualização dos estudos brasileiros. Revista Brasileira de Geriatria e Gerontologia, Rio de Janeiro, v. 13, n. 2, p. 321 328, ago. 2010. FapUNIFESP (SciELO). http://dx.doi.org/10.1590/s1809- 98232010000200016. 
